\title{
A DIDÁTICA NA FORMAÇÃO INICIAL DE PROFESSORES: RELATO DE EXPERIÊNCIA
}

\author{
LA DIDÁTICA EN LA FORMACIÓN INICIAL DE PROFESORES: RELATO DE \\ EXPERIENCIA
}

\author{
DIDACTICS IN INITIAL TEACHER EDUCATION: TEACHING PRACTICE \\ REPORT
}

Ivan FORTUNATO ${ }^{1}$

\begin{abstract}
RESUMO: Este artigo foi escrito na forma de ensaio a partir das experiências realizadas no ensino da disciplina de didática, do quinto semestre da licenciatura em física, e do segundo semestre da especialização em informática aplicada à educação, ambos cursos do Instituto Federal de São Paulo, campus Itapetininga. Sob o conceito de "missões" educativas, a disciplina de didática, nos dois níveis de ensino, foi realizada quase que na íntegra fora dos bancos escolares da educação superior, acontecendo no campo de atuação do professorado, ou seja, nas escolas. Na segunda metade do ano de 2017, estivemos em duas escolas estaduais, sendo uma técnica, e uma escola municipal, desenvolvendo diversas atividades de ensino de física e informática. Ao final, pode-se perceber que as missões não apenas servem para aproximar as escolas do local de formação de professores, como os próprios estudantes de licenciatura e pós-graduação conseguem compreender melhor a teoria pedagógica, sejam suas lacunas, sejam seus ideias de reflexão.
\end{abstract}

PALAVRAS-CHAVE: Formação de Professores. Ensino de didática. Relato de experiência.

RESUMEN: Este artículo fue escrito en la forma de ensayo a partir de las experiencias realizadas en la enseñanza de la disciplina de didáctica, del quinto semestre de la licenciatura en física, y del segundo semestre de la especialización en informática aplicada a la educación, ambos cursos del Instituto Federal de São Paulo, campus Itapetininga. En el concepto de "misiones" educativas, la disciplina didáctica, en los dos niveles de enseñanza, fue realizada casi íntegra fuera de los bancos escolares de la educación superior, pasando en el campo de actuación del profesorado, o sea, en las escuelas. En la segunda mitad del año 2017, estuvimos en dos escuelas estatales, siendo una técnica, y una escuela municipal, desarrollando diversas actividades de enseñanza de física e informática. Al final, se puede percibir que las misiones no sólo sirven para aproximar las escuelas del lugar de formación de profesores, como los propios

\footnotetext{
${ }^{1}$ Universidade Federal de São Carlos (Ufscar), Sorocaba - SP - Brasil. Instituto Federal de São Paulo (Ifsp), Itapetininga - SP - Brasil. Professor do Programa de Pós-Graduação em Ciências Humanas e Sociais (UFABC), do Programa de Pós-Graduação em Educação (UFSCar), Sorocaba e do IFSP, Itapetininga. Doutor em Geografia e doutor em Desenvolvimento Humano e Tecnologias, ambos pela Universidade Estadual Paulista (Unesp). Email: ivanfrt@yahoo.com.br.
} 
estudiantes de licenciatura y posgrado logran comprender mejor la teoría pedagógica, sean sus lagunas, sean sus ideas de reflexión.

PALAVRAS CLAVE: Formación de profesores. Enseñanza de didáctica. Relato de experiencia.

ABSTRACT: This paper was written in the form of an essay based on the experiments carried out in the teaching of the didactics course of the fifth semester of the undergraduate physics-teaching course, and of the second semester of the specialization in informatics applied to education, both from the Federal Institute of São Paulo, campus of Itapetininga, Brazil. Under the concept of educational "missions", the didactic discipline, at both levels of education, was carried out almost entirely outside the Federal Institute, taking place in the field of teaching, that is, in schools. In the second half of 2017, we were in two state schools, being one of technical education, and one municipal school developing various teaching activities both in physics and computer teaching. In the end, it can be seen that the missions not only serve to bring schools closer to the place of teacher education, but also undergraduate and graduate students themselves can better understand the pedagogical theory, be its gaps or its ideas of reflection.

KEYWORDS: Teacher Education. Didactics teaching. Experience report.

[...] será necesario que todo docente universitario asuma y se sensibilice interiorizando la docencia como una profesión educativa y sepa cuáles son las tareas pedagógicas necesarias para llevarla a cabo, cuáles son los aprendizajes relevantes, los medios didácticos de que dispone y qué debe hacer para facilitar en el alumnado el desarrollo de la capacidad de comprensión más que el de repetición ${ }^{2}$ (IMBERNÓN, 2016, p. 43).

É preciso concordar com o pressuposto da citação reproduzida na epígrafe: ser professor universitário requer o reconhecimento das contingências da profissão, principalmente as que dizem respeito ao seu propósito fundante, que é o aprendizado dos estudantes. É sobre esta circunstância que Imbernón (2016) apresenta seu alerta a respeito de fazer uso dos meios didáticos disponíveis, para que o alunado tenha condições de desenvolver seu aprendizado de uma maneira que as coisas sejam efetivamente compreendidas. Por isso, o autor é contrário à repetição. Eu também.

\footnotetext{
2 Tradução livre: Será necessário que todos os professores universitários assumam a responsabilidade e se sensibilizem, internalizando o ensino como profissão educacional e reconhecendo quais são as tarefas pedagógicas necessárias para realizá-la, quais são as aprendizagens relevantes, os meios didáticos disponíveis, e o que deve ser feito para facilitar aos alunos o desenvolvimento de habilidades de compreensão, mais do que a repetição.
}

RIAEE - Revista Ibero-Americana de Estudos em Educação, Araraquara, v. 13, n. 1, p. 269-276, jan./mar., $2018 .$. 
Assim, este artigo foi escrito na forma de ensaio a partir das experiências realizadas no ensino da disciplina de didática, desenvolvida com duas turmas distintas: a turma do quinto semestre da licenciatura em física, e a turma do segundo semestre da especialização em informática aplicada à educação, ambos cursos do Instituto Federal de São Paulo, campus Itapetininga. A condução desta disciplina foi lastreada pelo alerta do Imbernón (2016), ou seja, mais compreensão, menos repetição. Para tanto, foi preciso colocar em xeque longa vivencia escolar como estudante e considerável experiência como docente, totalizando mais de 20 anos de contato com o uso dos meios didáticos para mera repetição. Sem me alongar, mas, à guisa de um esclarecimento necessário, repetição é a forma mais tradicional de se trabalhar na escola: um professor conduz a dinâmica da aula, dando comandos para os estudantes, que devem reproduzir o que lhes é indicado, ou criar algo a partir de um escopo delimitado e alegórico.

A alegoria está quase sempre presente nas atividades escolares, pois estas nunca condizem com o mundo concreto da experiência, reduzindo-se a cenários e ambientes hipotéticos e/ou ideais. Tais constatações sobre o universo escolar, um tanto quanto ácidas e negativas, foram sendo construídas a partir da leitura de educadores que tinham uma visão mais otimista, não apenas da própria escola, mas da vida em si. Dessa forma, as reflexões que faço a respeito de uma educação escolar voltada mais para a compreensão do que para a repetição, sempre retornam aos ensinamentos de Neill (1978) e de Freinet (2004; 2001). Se em outros momentos de reflexão (FORTUNATO, 2016a; 2016b) tomei o ensaio como método para esmiuçar o sentido da escolarização, aqui o propósito é usar o mesmo procedimento para partilhar como essa reflexão pode se tornar ação pedagógica de fato.

O primeiro passo foi transfigurar o planejamento dessa disciplina. Assim, ao invés de consolidar antes e arbitrariamente o que seria apresentado e exigido como repetição a respeito de didática, a construção do plano foi deixada para as primeiras aulas, para que pudéssemos fazê-lo coletivamente. Outro aspecto fundamental para o desenvolvimento da disciplina era a apresentação de ambientes e contextos legítimos, nos quais a didática, como aplicação assertiva das técnicas de ensino, teria muito mais chances de ser compreendida. Dessa maneira, logo vislumbrei a possibilidade de alavancar ainda mais uma forma de ensinar a ensinar que já vinha sendo burilada. No semestre anterior, havia iniciado a experimentar o método com trabalhos de campo, no qual se gesta uma atividade educativa no conforto da sala de aula do ensino superior, e a 
coloca em prática em uma escola ou uma instituição de ensino não-formal (FORTUNATO, 2017).

Para ir além do que foi tateado no primeiro semestre, as atividades educativas a serem desenvolvidas no campo já não poderiam mais ser controladas, mas, emergir do próprio cotidiano escolar. Desse modo, cunhamos o conceito de "missões" para descrever cada um dos projetos educativos que foram planejados em articulação com alguma instituição de ensino, buscando atender uma demanda, emergencial ou potencial mas, autêntica. Foram, ao todo, oito missões realizadas ao longo do segundo semestre de 2017, em três instituições diferentes: uma escola municipal, do primeiro ciclo do ensino fundamental, uma escola estadual de ensino regular, e uma escola estadual técnica.

Nas primeiras aulas de didática, apresentei aos estudantes da licenciatura e da pós-graduação cada instituição a partir de um contexto específico, que foi estabelecido por meio de diálogo direto com o corpo diretivo local e/ou com respectivo supervisor na diretoria estadual de ensino da região ou secretaria municipal de educação. Esses diversos contextos foram colocados como uma possibilidade para a disciplina de didática, na qual poderíamos nos debruçar coletivamente sobre cada demanda, tentando apresentar uma possível solução educativa. Outra possibilidade dada aos estudantes foi a condução catedrática da disciplina, ou seja, aulas retóricas, leituras de trechos de obras clássicas, apresentação de seminários etc. A escolha pelas missões foi unânime.

O passo seguinte foi criar uma estratégia capaz de envolver as quatro dezenas de estudantes matriculados (nas duas turmas) e, ao mesmo tempo, dar conta de atender as demandas expostas pela direção de cada instituição. Para tanto, a solução mais prática foi a criação de equipes. Os estudantes decidiram se agrupar por afinidade pessoal e/ou pelo tema mais evidente em cada contexto. Com isso, tivemos missões desenvolvidas por grupos de seis integrantes e missões cumpridas por uma dupla. Alguns, inclusive, optaram por participar de mais de uma missão, seja pelo interesse no contexto e/ou pelo tema a ser trabalhado.

A etapa sequente foi elaborar um plano específico para cada missão. Com cada equipe, uma a uma, fomos projetando as atividades dentro de um cronograma ideal, detalhando as ações e a forma de avaliação contínua e global. Cada planejamento foi apresentado às respectivas direções e, quando necessário, ajustes foram feitos.

$\mathrm{Na}$ sequência, com os planos de ação prontos, partimos para as missões, procurando ocupar o período da semana que seria destinado para as aulas catedráticas, 
com intervenções realizadas no próprio campo de trabalho da formação que os estudantes buscam, ou seja, nas instituições de ensino.

As missões desenvolvidas no primeiro contexto transcorreram com pouquíssimos ajustes no cronograma e com elevado grau de aprovação, tanto pelos estudantes que aprendiam didática, quanto pelos estudantes da escola que nos acolhia, e pelo respectivo corpo diretivo. Foram três projetos distintos realizados com sucesso em uma escola municipal de ensino fundamental: (a.) cartografia virtual para as classes de quinto ano, (b.) reforço de alfabetização para estudantes em defasagem escolar, e (c.) curso de introdução digital para a turma da Educação de Jovens e Adultos (EJA). Eis os fatores mais importantes para que todas as propostas tenham sido executadas conforme o plano: o comprometimento da equipe gestora e do professorado, parceria anterior realizada com sucesso (cf. FALCHI; FORTUNATO, 2018), e engajamento dos membros das equipes.

No segundo contexto, duas missões voltadas para a formação de professores de uma escola técnica estadual foram conduzidas na forma de oficinas, em dois sábados distintos. Neste contexto, ambas as oficinas transcorreram dentro do cronograma estimado e a aceitação do público foi mais que satisfatória. As duas oficinas foram planejadas a partir de uma necessidade identificada pela direção da instituição e seus coordenadores: era preciso investir na formação docente continuada e na capacitação para o uso da tecnologia digital. Assim, cada equipe pode se especializar em uma ferramenta que já tinha afinidade, além de poder vivenciar vários aspectos da didática, ao ensinar professores a respeito do Google Classroom ${ }^{\circledR}$ e do Prezi ${ }^{\circledR}$.

Ao contrário dos dois primeiros ambientes propícios para a execução das atividades planejadas, o terceiro contexto nos ofereceu oportunidade ímpar de lidar com diversos imprevistos do cotidiano escolar. Foram acordadas três missões, sendo duas com foco no alunado do último ano e uma na formação de professores. Nenhuma missão transcorreu de acordo com o plano e diversos ajustes tiveram que ser realizados ao longo do semestre. Dessa maneira, nosso envolvimento com a escola estadual possibilitou vivenciar situações que não se encontram em nenhum livro de didática, apenas ampliando a compreensão da complexidade do universo educacional.

Antes do final do primeiro semestre deste ano, a supervisão de ensino me procurou para atender uma demanda específica da escola: motivar seus estudantes para se inscreverem, e participarem com afinco, do Exame Nacional do Ensino Médio (ENEM). Em reunião com a diretora, traçamos um plano que começava com uma 
palestra para toda população estudantil sobre os benefícios de se cursar uma faculdade, e seguia, mês a mês, com atividades voltadas para a continuidade dos estudos na universidade ou escola técnica. Incluímos, no rol de ações, a condução de uma palestra específica sobre as oportunidades de cursos técnicos e superiores gratuitos e suas formas de ingresso, além da aplicação de um teste vocacional, para facilitar a decisão dos jovens sobre sua vida futura vida profissional. Adicionamos outra missão: atividades de física, resolução de exercícios e a apresentação de um show de ciências, com experimentos diversos e interativos, e uma visita guiada ao campus do IFSP local, tanto para divulgar o instituto, como incentivar os egressos do ensino médio a buscarem sua formação superior na própria cidade. Ainda, o plano era mais robusto, envolvendo uma missão de formação do professorado na lista de atividades, pois sua motivação pode encorajar os alunos a continuarem os estudos.

Pois, às vésperas de se iniciar o projeto, a diretora mudou-se de cidade. Foi preciso, então, retomar o planejado com a nova responsável pela escola. Isso demandou tempo, o que tardou o começo do plano anterior. Mesmo com certa demora, iniciamos as missões. Não obstante, após palestra introdutória, a gestão da escola passou por sérios problemas com a administração e o alunado, levando à vacância temporária do cargo. Apesar da boa disposição do gestor interino, decidimos colocar todas as missões que envolveriam o alunado em apenso. Isso levou as equipes a um replanejamento das ações, encurtando os projetos. Mesmo assim, com todas as dificuldades, levamos a cabo o show de ciências e a visita monitorada no instituto e, na última semana de aula, conseguimos aplicar o teste vocacional, porém para uma fração mínima do total de estudantes.

Nessa situação atípica de troca de direção, o trabalho com o professorado também foi encurtado, restringindo-se a um treinamento prático do uso da lousa digital disponível na escola. A missão foi parcialmente bem sucedida, pois, a equipe que decidiu se aventurar nesta missão pôde vivenciar as dificuldades técnicas de se utilizar as tecnologias digitais na educação formal. Mesmo tendo visitado a escola semanas antes da efetiva data do treinamento, com vistas ao reconhecimento do equipamento e sua funcionalidade, a equipe passou pelo apuro de não conseguir conduzir o treinamento na íntegra. Isso porque a lousa digital e os computadores disponíveis (da escola e dos próprios estudantes de didática) estavam com problemas de compatibilidade. Foi preciso, então, localizar na internet novo software de instalação da lousa digital para sanar tal condição. Tal delonga, no entanto, não minimizou o crédito positivo da missão, 
pois tanto o professorado quanto os coordenadores reconheceram a importância de ver a lousa digital em funcionamento efetivo, depois de anos instalada na escola sem ter sido sequer ligada.

Sendo assim, quando o semestre encerrou, todas as equipes se reuniram em uma aula de partilha e avaliação. O objetivo era aprender, tanto com a própria missão, quanto com as missões de seus pares, a didática vivida em diversos, porém concretos, cotidianos educativos. Nada foi reproduzido, ao passo em que muito a respeito do uso assertivo das técnicas de ensino pode ser compreendido pelos estudantes. Em essência, foi consenso que a forma de trabalho pedagógico por meio de missões é desafiador, porém gratificante. Ficou patente a importância do planejamento, mas, também, da flexibilidade nas ações por conta do imprevisto: pode ser necessário improvisar, como nos casos em que a tecnologia não corresponde ao esperado, ou pode ser exigido reformulação das ideias iniciais. Por fim, ficou patente que a proposta de sair da sala de aula para explorar o mundo concreto das situações educacionais foi não apenas interessante, como se mostrou necessário para uma formação crítica das práticas pedagógicas.

Ao final, pode-se perceber que as missões educacionais servem não apenas para aproximar as escolas do local de formação de professores, como os próprios estudantes de licenciatura e pós-graduação conseguem compreender melhor a teoria pedagógica, sejam suas lacunas, sejam seus ideias de ação e reflexão.

\section{REFERÊNCIAS}

FALCHI, L.; FORTUNATO, I. Simulador PHET e o ensino da tabuada na educação básica: relato de experiência. Revista on line de Política e Gestão Educacional, Araraquara, v. 22, n. 1, 2018. [no prelo]

FORTUNATO, I. Ensinando futuros professores a ensinar: relato de experiência. 2017. [artigo submetido].

FORTUNATO, I. Aprendendo com Célestin Freinet: o passado ainda é presente. Tendencia Pedagógicas, Madrid, v. 27, n. 1, p. 251-258, 2016 a.

FORTUNATO, I. Ainda é preciso ter cuidado: escola?!. InterScience Place, Campos dos Goytacazes, v. 11, n. 2, p. 86-95, 2016 b. 
FREINET, C. Pedagogia do bom-senso. Trad. J. Baptista. 7. ed. São Paulo: Martins Fontes, 2004.

FREINET, C. Para uma escola do povo: guia prático para a organização material, técnica e pedagógica da escola popular. Trad. Eduardo Brandão. São Paulo: Martins Fontes, 2001.

IMBERNÓN, F. Mejorar la enseñanza y el aprendizaje en la universidad. São Paulo: Edições Hipótese, 2016.

NEILL, A. S. Um mestre contra o mundo: o fracasso que floriu numa nova escola. Trad. Aydano Arruda. São Paulo: IBRASA, 1978.

\section{Como referenciar este artigo}

FORTUNATO, I. A didática na formação inicial de professores: relato de experiência. Revista Ibero-Americana de Estudos em Educação, Araraquara, v. 13, n. 1, p. 269276, jan./mar., 2018. E-ISSN: 1982-5587.

Submetido em: 21/12/2017

Aceito em: 03/01/2018 